\title{
Proyección territorial y lugares sagrados: el rol legitimador de la religión en Arabia Saudita
}

\author{
Territorial projection and sacred sites: the \\ legitimizing role of religion in Saudi Arabia
}

\author{
Santiago Mesa Castaño*
}

\begin{abstract}
RESUMEN
Basándose en la historia de Arabia Saudita y la fijación territorial de la misma, el presente trabajo desarrolla marcos analíticos en donde la religión se consolida como un elemento de análisis de la geografía política. A partir de estos, se toma en cuenta el manejo estratégico de la religión como base fundamental en la unificación territorial e identidad nacional, especialmente en el rol saudí de ser el guardián de los territorios sagrados para el islam, la importancia de esta tarea parte de la justificación de su existencia y legitimidad frente a la comunidad musulmana global.
\end{abstract}

Palabras Clave: Geopolítica - Arabia Saudita - Islam - Religión Construcción de Estado.

Internacionalista y Magister en Estudios Políticos e Internacionales. Universidad del Rosario. Bogotá, Colombia. Correo: santiago.mesa@urosario.edu.co. ORCID: 0000-0003-3235-018X. Recibido: 18 de septiembre de 2019. Modificado: 13 de abril de 2020. Aceptado: 14 de abril de 2020. 


\begin{abstract}
Based on the history of Saudi Arabia and its territorial fixation, the present work develops analytical frameworks where religion is consolidated as an element of analysis for political geography. From these, the strategic use of religion is considered as a fundamental basis in the territorial unification and national identity, especially in the Saudi role as the guardian of the sacred territories for Islam, the importance of this task is based on the justification of its existence and legitimacy vis-á-vis the global Muslim community.
\end{abstract}

Keywords: Geopolitics - Saudi Arabia - Islam - Religion - State building.

\title{
I.- GeOPOLÍTICA Y RELIGIÓN
}

En primera medida es necesario contemplar el alcance de la religión en la idea fundacional y constitutiva de un Estado. Los espacios representados con un valor estratégico importante pueden tener una conexión especial mientras exista algún discurso religioso que vincule una extensión de terreno como tierra santa o bien un lugar como un sitio santo. Incluso, más allá de un interés estratégico, estos lugares santos toman importancia en tanto su historia y espiritualidad.

Existe así una relación entre la geografía y la proyección territorial de un Estado. Un lugar es considerado santo en tanto es "el sitio de eventos sagrados del pasado o para el cumplimiento de una profecía, y tiene un rol definitorio de los fieles en la identidad y ethos religioso" (Stump, pág. 309, 2008). En este sentido, la geografía y la historia son relevantes, pues dan un sentido y valor espiritual a dichos espacios. Para estos territorios santos, la importancia estratégica está en el significado que la historia de su religión le ha otorgado, un territorio que sin dicho complemento no tendría un valor estratégico extra.

En el estudio de la geopolítica y la religión, Sturm (2013) proporciona cuatro marcos analíticos que permiten dar una interpretación a la geografía política de los Estados, incluso los que son considerados seculares. El primero es dar paso a una explicación sobre la geopolítica y sus orígenes; el segundo explora la religión como un elemento integral en la construcción de visiones geopolíticas; el tercero dice que existe una tipología religiosa en la geopolítica, y el cuarto es una construcción análoga de la religión como geopolítica. El presente trabajo se enfocará en los marcos de la religión como elemento y tipología en las construcciones geopolíticas (Sturm, 2013). 
La religión como elemento que define una imagen geopolítica constituye una forma de relacionar cómo la religión "proporciona mitos que son centrales en los imaginativos geopolíticos" (Sturm, pág. 138, 2013). Por esto, el autor afirma que dejar de lado el lenguaje, el entorno, la raza o la etnicidad es un error, pues estos elementos dan sentido a la geografía política en un Estado, aún más cuando la religión se constituye como elemento del imaginario geopolítico.

Conectado con el marco analítico anterior, Smith (2000) propone cuatro dimensiones del carácter sagrado en las naciones: elección étnica, territorio sagrado, etno-historia y sacrificio nacional. De las categorías mencionadas, la elección étnica y el territorio sagrado se relacionan con la proyección geográfica, por una parte, porque hay una aceptación de que existe una 'misión'en donde una comunidad es escogida por alguna deidad para cumplir un propósito terrenal materializado en el asentamiento, la defensa, la conversión o la expansión. Por otra parte, hay un 'pacto' en donde la deidad escoge una comunidad y promete beneficios a cambio de obediencia, siendo el más llamativo el caso de los judíos y la promesa de una tierra prometida (Smith, 2000).

En relación con un territorio sagrado, como se ha mencionado en párrafos anteriores, su importancia espiritual e histórica generan un valor mayor y "el pasado de la comunidad se vuelve una parte integral del entorno natural (...), la etnia o comunidad étnica se vuelve parte de ese entorno y hábitat, estos últimos pertenecen y se constituyen en una parte integral de la comunidad" (Smith, pág. 806, 2000).

Este marco analítico permite considerar que una tipología denominada geopolítica religiosa, parte de la necesidad de contemplar una geopolítica diferente a la secular. Este marco permite pensar que más allá de una retórica y lenguaje religioso, existe una geopolítica religiosa diferente a una secular, pues "ignorar la religión en las relaciones internacionales y la geopolítica, implica una teoría de secularización que postula que las raíces del sistema de Estados soberanos emergieron desde la diferenciación de la religión" (Sturm, pág. 138, 2013).

Por esto, la religión y los Estados modernos se constituyen mutuamente, pues "la normatividad y jerarquías verticales espirituales de espacio sagrado justificaron acciones imperialistas y jerarquías horizontales del espacio geopolítico" (Ó Tuathail, pág. 188, 2000). Con una ruptura de la imaginativa geo-religiosa de la época medieval, surge la disposición geopolítica secular del sistema de Estados modernos, es decir, se cuestiona una ruptura radical entre secularidad y espiritualidad. El punto de análisis interesante es que la religión forma parte importante en la imagen geopolítica de un Estado porque, incluso en las sociedades seculares, están infundidas creencias míticas propias del desarrollo religioso (Sturm, 2013). 
La proyección política y geográfica de un Estado logra tener influencia de los imaginarios de la religión. Sin embargo, no es prudente afirmar que dichos imaginarios determinan su rumbo. Por esto, la división entre religión y geopolítica logra ser más coincidente o justificadora, por ejemplo, las “ideas nacionalistas o imperialistas pueden fácilmente resonar con antiguos reflejos religiosos, pero apoyar en dichas ideas las decisiones oficiales de política exterior ya había sido escandaloso en la escena diplomática del siglo xvir" (Dijkink, Pág. 205, 2006).

Así, para analizar la relación que puede existir entre religión y constitución territorial es necesario reconocer en qué momentos la religión sirve para la consolidación de un Estado. Esto ocurre cuando la importancia estratégica de un territorio puede explicarse por su importancia simbólica de tierra santa o sitio santo (Stump, 2008), no solamente por su localización y geografía física.

El caso de Arabia Saudita toma relevancia en este marco analítico, pues la construcción de un Estado bajo los ideales promovidos por el Rey Ibn Saud logran tener una explicación sustancial frente a la presencia de la religión en su consolidación territorial.

\section{II.- Consolidación territorial de Arabia Saudita}

La formación del Estado de Arabia Saudita no se puede entender sin el papel unificador del islam aplicado por la dinastía saudí. El ideal religioso del islam para la dinastía saudí toma sentido con la apropiación del wahabismo como principio rector en las comunidades. El wahabismo surge con la oratoria del reformador Abd al-Wahab en el siglo xviII, el cual predicaba una estricta obediencia del Corán, su introducción en la península arábiga central toma relevancia por la alianza entre Al-Wahab y Muhammad ibn Saud en 1744, con el fin de que la comunidad de Diriyya viviera bajo esta orientación islámica, dando como resultado una centralización de los grupos pastoriles y el rechazo a los intereses otomanos (Hourani, 2014). Es importante resaltar que dentro de las enseñanzas del wahabismo predominó la idea de jihad (sentimiento de pertenencia a la comunidad y deber responder al llamado de protegerla) y de zakat (pilar del islam que promueve la aportación de donaciones), siendo estos fundamentos esenciales para la expansión y nueva conquista de territorios en cabeza de Ibn Saud desde Riyadh en 1902.

La consolidación del Estado de Arabia Saudita se inicia en 1902 y finaliza en 1932, mediante un proceso de unificación territorial bajo el mando militar, político y social de 'Abd al- 'Aziz ibn 'Abd ar-Rabman $\bar{A} l S a^{\prime} \bar{u} d$, popularmente conocido como Ibn Saud. 
La unificación de Arabia Saudita se da en medio del conflicto entre la dinastía Rashidi que asentaba su poder en la ciudad de Riyadh y contaba con apoyo del Imperio Otomano, y la dinastía Saud, la cual hasta 1902 estuvo exiliada en Kuwait y tenía el apoyo del Imperio Británico. Es decir, no solo se vinculaban intereses de las dinastías provenientes de la península arábiga, sino también es necesario tener en cuenta los intereses en la región de los imperios mencionados.

La primera medida que toma Ibn Saud es arrebatar el control de la ciudad de Riyadh de los Rashidi y, con esto, iniciar una expansión territorial desde el centro de la península arábiga [ver el Anexo 1]. Una campaña de aproximadamente 60 combatientes conquista Riyadh en 1902, iniciando una serie de batallas que lograrán consolidar el control sobre el futuro reino. Entre 1902 y 1906, las campañas militares dan control sobre la península arábiga central a Ibn Saud al presionar a los nuevos gobernantes de la región de Hail (al norte de Riyadh) de concebir un acuerdo para retirar las fuerzas otomanas de los nuevos territorios anexados (Wynbrandt, 2004).

En poblaciones sedentarias en la región Nadj, en el centro de la península arábiga, agrupaciones de personas conocidas como mutawwas promovían la obediencia y ejecución del islam. Gracias a esto se tomó un rumbo favorable, pues "históricamente las figuras religiosas de Nadj usualmente estudiaban, enseñaban y aplicaban únicamente Hanbali fiqh (jurisprudencia islámica), considerando otras ramas religiosas y ciencias lingüísticas como lujos intelectuales que no eran necesitadas en su propia sociedad" (Al-Rasheed, Pág. 48, 2010). Un apoyo de estas características dio a Ibn Saud una base de control social y de legitimidad al momento de conquistar Riyadh, esta ciudad lo declaró imam y las siguientes batallas por el control de la península se basarían en las imágenes y mitologías centradas en el wahabismo y la virtud de expandir estas enseñanzas del islam (Al-Rasheed, 2010).

Esta primera fase de expansión y control territorial dispone a la península arábiga central como base estratégica para las futuras anexiones. El control del centro de la península arábiga daba una ventaja a Ibn Saud pues consolidaría una fuerza militar formidable y, al mismo tiempo, asentaría sus bases de control social bajo la consolidación del wahabismo. En la región central de la península arábiga permanecía la base social y religiosa, la religión como elemento constitutivo de imágenes geopolíticas tiene un arraigo en la alianza Wahab-Saud de 1744, que lograba dar sentido a un proceso de elección étnica (Sturm, 2013) para cumplir una misión materializada en la consolidación de un territorio bajo las enseñanzas y rituales del islam para su posterior extensión, de la mano de Ibn Saud.

Con el centro de la península arábiga bajo control de Ibn Saud, los mutawwas adquirieron mayor 
participación política, económica y social, dado que antes de la toma de Riyadh no tenían poder alguno pues sus esfuerzos se concentraron en preservar el legado de Al-Wahab. Esto cambió con la conquista de Ibn Saud pues fueron empleados con la finalidad de ser especialistas en la aplicación de rituales islámicos como recitar el Quran sin que necesariamente fuese entendido (dado los altos índices de analfabetismo), realizar rituales de purificación sin tener agua y promover la obediencia mediante el pago del zakat y la respuesta al llamado de la $j i$ had (Al-Rasheed, 2010). La alianza Wahab-Saud de 1744 no solo daría sentido al proceso de elección étnica del cual contaban los mutawwas para cumplir su misión de mantener vivo el wahabismo, la alianza igualmente generó legitimidad política y religiosa a Ibn Saud en la medida que se garantizase continuidad y defensa a la interpretación ritualista del islam.

Junto con la base religiosa de $m u$ tawwas, la consolidación de las fuerzas militares se organizó bajo la figura ikhwan, que eran beduinos de diferentes clanes tribales en la región de Nadj. El principal problema para generar un acercamiento con los clanes tribales era que "previamente, entre las tribus de Nadj frecuentemente se atacaban, asesinaban y también rechazaban cualquier control impuesto sobre ellos, desde gobiernos otomanos o cualquier soberano en la península arábiga” (Al-Azma', Pág. 76, 1999). La religión lograría agrupar estos clanes tribales, a partir de 1912 Ibn Saud recibió a los clanes en Riyadh dando espacio para que apropiaran los valores y rituales religiosos del islam.

Los clanes tribales adoptaron una vida sedentaria y se organizaron en asentamientos de aldeas o hujar en remembranza de la migración del Profeta Mohammad de Meca a Medina y en consecuencia, el establecimiento de los beduinos en asentamientos iba a garantizar que más guerreros tribales se unieran a la causa de Ibn Saud (Wynbrandt, 2004). Los clanes que se organizaron sedentariamente recibieron enseñanzas religiosas que incluían las obligaciones litúrgicas del islam según la idea islámica wahabí, al mismo tiempo que inculcaban la necesidad de vincular su lealtad hacia el imam Ibn Saud y el requerimiento de respuesta del llamado de la jihad (Al-Rasheed, 2010).

La idea del actual Estado Saudí toma forma al unificar comunidad y fuerza militar bajo las ideas e imaginarios del islam, siendo el wahabismo una fuente de legitimación bajo el liderato de Ibn Saud. Sin duda puede pensarse en la idea de una geopolítica religiosa en este caso (Sturm, 2013) pues la religión y el control político están de la mano en la consolidación territorial de Arabia Saudita. Para Arabia Saudita el islam se movilizó con el fin de proteger el Estado y el wahabismo no solo moldeó la identidad de las personas, sino también 
los valores nacionales. Por esto, por establecimiento estricto, solo musulmanes pueden ser ciudadanos saudís (Nevo, 1998).

Con una fuerza militar wahabi bajo el mando de Ibn Saud se inicia un nuevo ciclo de conquistas territoriales. El principal impedimento era la presencia otomana, pero al finalizar la Primera Guerra Mundial el imperio iba a decaer. El tratado anglo-saudí de diciembre de 1915 reconoce la autoridad de Ibn Saud sobre Nadj, Hasa, Qatif y Jubayl (centro y este de la península arábiga), además de concederle armas y dinero con la condición estipulada de no interferir en los otros protectorados británicos en la zona, es decir Kuwait, Bahréin, Qatar y Omán (Al-Rasheed, 2010).

La dinastía Rashidis y la familia real Hashemita eran los siguientes obstáculos. En 1921 los saudís conquistaron la ciudad Hail, base de poder Rashidi, logrando extender su control territorial al norte y en 1925 tomaron la provincia de Hijaz donde la familia real Hashemita gobernaba. Estas conquistas son claves, pues "era la primera vez que esas cuatro regiones, Nadj, Hasa, Hijaz y 'Asir (...), quedaron bajo dominio de un único gobernante desde el emirato Saudi-Wahabi del siglo xviII" (Al-Rasheed, Pág. 44, 2010).

La proyección territorial fue posible con la ayuda de la religión y el inculcamiento del wahabismo en las zonas anexadas. Ahora bien, con la anexión de la provincia de Hijaz (noroeste de la península) se da un paso importante, las ciudades santas de la Meca y Medina quedan bajo el control saudí.

\section{a. Meca y Medina: proyección territorial y legitimación musulmana}

Según la religión musulmana, en el año 610 el ángel Jibril revela una serie de mandatos divinos - el Quran - al profeta Muhammad en la ciudad de la Meca, quien al predicar el mensaje divino atrajo pocos seguidores y muchos enemigos, al punto que Muhammad y 200 seguidores tienen que migrar a Medina. Allí tienen un éxito contundente, Medina sería la primera ciudad islámica hasta que en el año 630 deciden retornar a la Meca, viaje que se establecería como base del pilar islámico del Hajj, la peregrinación de los musulmanes a la Meca (Stump, 2008).

En 1925, la Meca y Medina quedan bajo el control de Ibn Saud y ahora las ciudades sagradas quedan en custodia del reino saudí, una oportunidad única para legitimar la existencia de la familia saudí como protectores de los principales lugares sagrados del islam.

La conquista de Hijaz en 1925 y, por defecto la Meca y Medina, tuvo el fin de controlar estos territorios sagrados bajo una autoridad islámica legítima, capaz de administrar su importancia. Por esto Ibn Saud declaró que "el propósito de la invasión de Hijaz era garantizar la libertad de perenigraje y establecer el destino de la Tierra Santa de manera satisfactoria al mundo islámico"(Al-Rasheed, Pág. 44,2010).Con 
la conquista de Hijaz se establecen códigos, reglas y normas legales islámicas, buscando asegurar las rutas de las peregrinaciones, además de establecer la 'Liga para el estímulo de la virtud y la prevención del vicio' para disuadir las practicas incompatibles con las enseñanzas wahabíes (Wynbrandt, 2004).

Meses después de la conquista de Hijaz, Ibn Saud deja en claro que "con el fin de probar a los líderes árabes y a las naciones musulmanas que él iba a ser el guardián de Al-Hayamayn (los dos lugares sagrados en la Meca y en Al-Madinah Al. Munawarah)" (Al-Azma', Pág. 164, 1999). Tener bajo su administración territorios sagrados (Smith, 2000) como la Meca y Medina busca legitimar frente a la comunidad islámica a Arabia Saudita y a la familia real saudí. Sin embargo, esta tarea de legitimación encontraría oposición. Al establecer una buena relación con los vecinos, emergieron disputas internas pues los ikhwan, siendo más fanáticos y ortodoxos, disputarían a la familia real saudí el rol de ser un legítimo protector de los principios islámicos.

Los ikhwan fueron los principales en desafíar a la monarquía por las progresivas campañas de modernización del país, por la continua expansión territorial y por buscar establecer mejores relaciones con los vecinos, los cuales eran considerados infieles. Las primeras revueltas $i k h w a n$ fueron acabadas en 1930 con ayuda de los británicos, a los cuales no les convenía ver una expansión de rebeldes fanáticos y ortodoxos en sus territorios protegidos de Kuwait e Irak (Al-Rasheed, 2010). Episodios de rebeldía se extenderían hasta 1979 con la captura de la Gran Mezquita en la Meca, siendo este un golpe contundente a la legitimidad de Arabia Saudita como protector de los territorios sagrados.

La toma de la Gran Mezquita fue encabezada por Juhayman al-Utaybi, quien mantuvo una postura islámica absolutamente radical. Los ikhwan criticaban al reino el "uso de tecnología moderna y su interacción con occidente, además del abandono de la jihad por razones de realpolitik" (Hegghammer \& Lacroix, Pág. 102, 2007). En una época donde el Reino de Arabia Saudita proponía cambios y modernizaciones gracias a las altas ganancias del petróleo, la dinastía saudí estaba en un momento de crisis de legitimidad, pues había tomado un territorio sagrado y base fundacional del islam, el cual era su deber proteger.

El liderazgo político de Arabia Saudita se vería afectado, pues en un espacio de pocos meses ocurre la toma de la Meca, además de revueltas de shiitas inconformes en zonas de control petrolero (Hegghammer \& Lacroix, Pág. 112, 2007). Entre 1979 y 1980, las tensiones en Arabia Saudita se manifestaron en la necesidad de reconciliar las altas ganancias del petróleo con las pautas del islam y hacer compatible el dogma religioso con las políticas del reino (Al-Rasheed, 2010).

Arabia Saudita necesitaba afianzar su papel de protector de los sitios sagrados, esto solo se lograría con el 
afianzamiento del wahabismo como religión e identidad del Estado, sin importar las modernizaciones de infraestructura y finanzas modernas. En este caso, religión e identidad nacional no pueden separarse pues:

...en los últimos 250 , el wahabismo ha provisto a la Casa de Saud no solo éxitos militares y ganancias territoriales, también legitimidad (...). La religión sigue siendo la base de su legitimidad, junto con el factor tribal dinástico. Que el rey reciba su poder y autoridad de esas fuentes se refleja en sus títulos oficiales: no es solo el rey del Reino de Arabia Saudita, también es imam al-wabhabiya and shaykh al-mashayikh (jefe de los jefes tribales) (...) Cultivando una identidad nacional donde la religión, como la lealtad a la Casa de Saud, se constituye como uno de los diferentes componentes necesarios para alcanzar esta meta. (Nevo, Págs. 45-46,1998) (traducción propia).

Del mismo modo, Arabia Saudita es el único Estado en el cual "su santidad se extiende en su territorio en la medida que sus gobernantes expresan una responsabilidad especial por el carácter islámico del Estado" (Dijkink, Pág. 198, 2006). Su legitimación como guardián de los lugares sagrados del islam es concebida por la identidad musulmana de la dinastía saudí y su compromiso como protectores de cualquier variación o contaminación de los preceptos del islam. En este sentido, Arabia Saudita ha mantenido el rol de protector al lograr pasar la crisis de la toma de la Gran Mezquita de 1979 y mantener una idea religiosa adherida a la identidad del Estado, a pesar de las riquezas y vínculos con países occidentales y especialmente desde de descubrimiento y explotación de petróleo.

La noción de territorio sagrado tuvo un papel importante para legitimar las anexiones territoriales de Arabia Saudita durante la primera mitad del siglo xx. La conquista de la Meca y Medina ubica a la dinastía Saud como protectora de los sitios sagrados del islam, simbólicamente busca legitimar su presencia como el guardián de las ciudades y protector del perenigraje o hajj hacia Kaaba en la Meca, a tal punto que el Rey de Arabia Saudita recibe en su investidura el título de 'Custodio de las dos Mezquitas Sagradas'. Al pensar la fundación y expansión de Arabia Saudita de la mano de la identidad religiosa del wahabismo, permite legitimarse ante la comunidad musulmana como verdadero guardián de los sitios sagrados, una aplicación estricta y acorde del islam, manteniendo modernizaciones bajo los estándares religiosos ha llevado a armonizar la identidad nacional con religión (particularmente la versión wahabí) y obediencia a la dinastía Saud, del mismo modo que el islam se moviliza para identificar y proteger al Estado y, por ende, los sitios sagrados que tiene en su territorio. 


\section{III.- Conclusión}

El caso de Arabia Saudita es particular al analizar la importancia de la religión en la proyección de territorio y conformación de una identidad nacional. El islam y especialmente el wahabismo son fuentes y bases legitimadoras para la existencia de Arabia Saudita bajo la administración de la dinastía Saudí. Igualmente es un caso especial, en tanto su proyección territorial aglomeró a la Meca y Medina, territorios santos del islam que proponen una tarea de legitimación ante la comunidad musulmana como dignos y capaces guardianes. De esta forma, la religión y la noción de territorio están ligadas. No se puede analizar la existencia e identidad nacional y territorial de Arabia Saudita sin las imágenes geopolíticas del islam a lo largo de su historia.

Legitimar la autoridad de los saudís ha sido un proceso histórico donde la religión ha sido la base fundacional del Estado de Arabia Saudita. Mediante anexiones territoriales y la consolidación de una comunidad seguidora de las enseñanzas wahabíes, solo se puede concebir a Arabia Saudita como una realización de la dinastía Saudí, que desde el siglo xviıI — con el wahabismo- consolidan su identidad fundacional.

Eventos como la toma de la Meca de 1979 le demostraron a la familia real saudí que los valores islámicos y wahabíes serían fundamentales para garantizar su legitimidad.La principal encrucijada sería reconciliar estos valores con su política energética, sus estrategias de modernización y la forma de entablar relaciones con países de occidente. Con la Meca y Medina bajo la administración de Arabia Saudita, el principal reto es demostrar ante la comunidad musulmana que la familia real saudí es guardián digno de los lugares sagrados del islam y que está capacitada para proteger estos sitios sagrados, además de garantizar las condiciones óptimas para que la perenigración se efectúe siempre.

De esta forma, la religión como elemento geopolítico y una geopolítica religiosa son marcos analíticos pertinentes en la consolidación y protección territorial de Arabia Saudita. Desde las primeras imágenes geopolíticas del territorio saudí bajo control de los preceptos wahabís, hasta la protección de territorios santos, la religión es una imagen que construye la idea del Estado saudí. Por esto la identidad de Arabia Saudita es la religión. No se puede pensar en la existencia del Reino sin tener en cuenta los valores religiosos del islam, hasta el punto de que ser musulmán es requisito para ser ciudadano.

Finalmente, es necesario resaltar que el papel del petróleo para Arabia Saudita ha generado una nueva proyección geográfica y económica en la zona y en el sistema internacional. Para posteriores estudios se puede investigar el papel de la religión en las 
políticas financieras y estratégicas del islámicos —sukuk—o la influencia Reino, por ejemplo, analizar las im- de doctrinas religiosas en el comerplicaciones de la emisión de bonos cio exterior.

Anexo 1

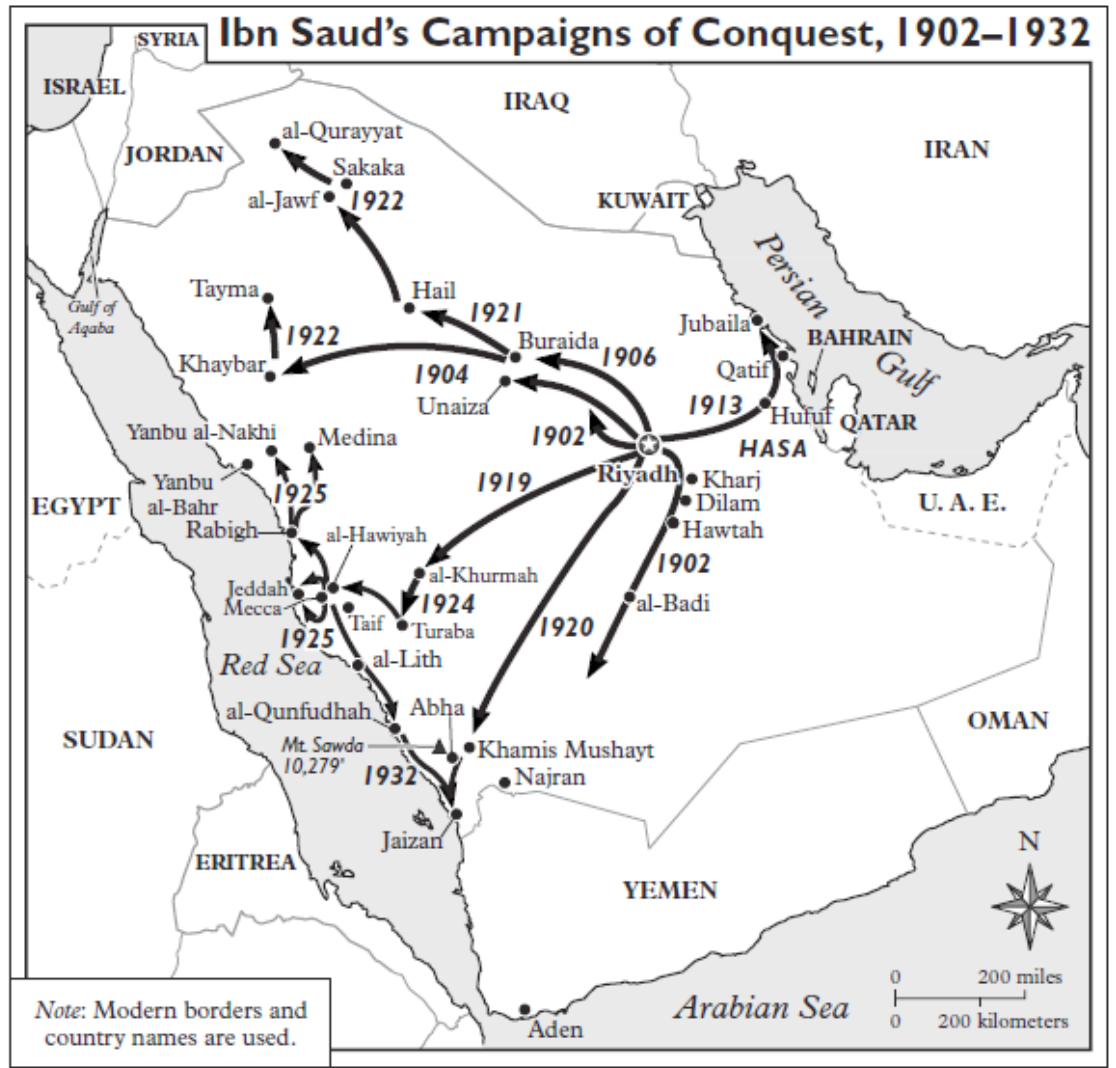

Tomado de (Wynbrandt, 2004).

\section{Bibliografía}

Al-Azma,'T. S. (1999). The role of the Ikhwan under 'Abdul-'Aziz Al Sa'ud 1916-1934. Centre for Middle Eastern and Islamic Studies-Durham University. Recuperado de: http://etheses.dur.ac.uk/1472/1/1472. pdf 76
Al-Rasheed, M. (2010). A history of Saudi Arabia. London: Cambridge University Press.

Dijkink, G. (2006). When Geopolitics and Religion Fuse: A Historical Perspective. Geopolitics, 11(2), 192-208. 
Hourani, A. (2014).La Historia de los Árabes. Barcelona: B. de Bolsillo.

Hegghammer, T. y Lacroix, S (2007). Rejectionist Islamism in Saudi Arabia: The story of Juhayman Al-Útaybi revisited. International Journal of Middle East Studies, 39, 103-122

Nevo, J. (1998). Religion and national identity in Saudi Arabia. Middle Eastern Studies, 34(3), 34-53.

Ó Tuathail, G. (2000). Spiritual Geopolitics. In K. Dodds, \& D. Atkinson (Eds.), Geopolitical Traditions (pp. 187-209). Routledge.
Smith, A. (2000). The 'Sacred' Dimension of Nationalism. Millennium: Journal of International Studies, 29(3), 791-814.

Stump, R. (2008). The Geography of Religión: faith, place and space. Maryland: Rowman \& Littlefield Publishers INC.

Sturm, T. (2013). The future of religious geopolitics: towards a research and theory agenda. Area (C) Royal Geographical Society, 45(2), 134-140.

Wynbrandt, J. (2004). A Brief History of Saudi Arabia. New York: Facts On File. 